\title{
THE IDENTIFICATION OF NEROTIC BEHAVIOR IN INDUSTRY
}

\author{
R.H. BROPHEY \\ VOCATIONAL SECTION \\ S.A. RAILWAYS \& HARBOURS
}

\section{OPSOMMING}

\begin{abstract}
Sommige van die praktiese probleme in verband met die identifisering van die neurotiese werker word bespreek en twee identifiseringsmetodes wat aan die vereistes van wetenskaplikheid en akkuraatheid voldoen nl. (1) kliniese identifisering en (2) psigometriese identifisering word kortliks behandel. Die tekortkominge en sterkpunte van kliniese identifisering, wanneer die bevindings vir bedryfsnavorsing benodig word, word met sekere voordele en nadele van psigometriese identifisering gekontrasteer.
\end{abstract}

There is a tremendous amount of literature in circulation which, in general, creates a poor impression of the person with a neurotic personality structure. This literature creates a negative expectation in respect of the neurotic in the work situation. This is not necessarily correct as the results of an investigation into the effectiveness of the neurotic worker compared to the non-neurotic worker show (Brophy and Raubenheimer, 1978).

\section{THE PROBLEM OF IDENTIFICATION}

Although neurotic behaviour has been accurately described and thoroughly studied for many decades, the proper identification thereof remains somewhat elusive.

The problem of the identification of neurotic behaviour for industrial research purposes within an organisation poses certain practical problems. Research in both America (Coville et al, 1960, pp. 100-101) and Great Britain (Tredgold, 1963, p. 26) indicate that the incidence of neurosis is much wider than that reflected on sickness certificates. This is partly because it is characteristic of the neurotic to go through life continually seeking treatment for physical illnesses whilst rejecting any diagnosis that is psychologically oriented and partly because many doctors, with the best of intentions, disguise a psychiatric diagnosis to protect their patients from stigma. In view of this, and as there is no reason to expect that the position in South 
Africa will be any different, it is obvious that very little will be achieved by scanning personnel sick records. A more scientific and accurate method of distinguishing neurotic from non-neurotic workers must therefore be employed.

The only two means which present themselves and which comply with the requirements of being both scientific and accurate are: (1) clinical identification, and (2) psychometric identification.

\section{METHODS OF IDENTIFICATION OF NEUROSIS}

\section{Clinical identification}

The clinical identification of neurotic behaviour is the traditional method, pioneered by Sigmund Freud and adapted and improved by psychoanalysts and psychologists ever since. It involves a formal interview or series of interviews (which are sometimes augmented by qualitatively scored instruments) between an individual and a person trained in one of the acknowledged fields of psychology. During these interviews the psychologist uses his training and experience to search for and identify symptoms present in the individual which are typical of the neurotic personality structure. On the basis of such symptoms as he may identify and the extent to which they are present, he makes a decision as to whether or not the individual can be classified as neurotic.

Although clinical identification has successfully been used over many years by clinical psychologists for psychotherapeutic work, this method has serious shortcomings when the findings are required for industrial research, however, and these shortcomings are briefly discussed below.

\section{Subjectivity}

An important consideration when evaluating clinical identification of neurosis is the subjectivity of the technique.

The clinical identification of neurosis is not an exact science but is an approach whose effectiveness is dependent to a very large degree on the school of training, competence and experience of the evaluator concerned. The boundary between a neurotic and a normal personality structure is not all that clearly defined an area and it has not been unknown for psychologists to disagree, sometimes vehemently, on a diagnosis in a specific case. Where the 
evaluation is required for therapeutic purposes modifications of the diagnosis can be introduced at any stage as the therapeutic process progresses.

In the case of research, however, unambiguous identification which is not subject to subsequent modification as the investigation progresses is required. There must be sufficient confidence in the identification process for the research process to proceed unhampered.

\section{Highly trained staff}

Clinical identification of a neurotic personality structure requires the services of highly trained staff. They must be at a minimum graduates in one of the acknowledged branches of psychology and persons who have both post-graduate qualifications and the requisite practical experience to be able to perform the task adequately. These are not only senior and highly paid individuals, but their numbers are of necessity limited, even in very large organisations. In addition they have a multitude of other important tasks concerned with the effective day-today running of the organisation to perform and pure research must be slotted into such time as may be available after this essential aspect has been catered for.

\section{Individual identification}

Clinical identification takes place in a one-to-one relationship between a psychologist and the person being evaluated. From the very nature of the identification process, staff cannot be evaluated for neurosis en masse. Where a large number of persons have to be evaluated by a single investigator, the impracticability of the situation is obvious.

\section{Facilities for observation}

Certain minimum facilities for observation and interviewing are necessary in order to be able to conduct satisfactory clinical evaluations. There are some work circumstances, however, where the creation of the necessary facilities can create almost insurmountable problems. This is particularly so when the staff to be interviewed perform duties outside in the open air and spread out over a large geographic area.

\section{The temporal factor}

In order to differentiate neurotic workers from non-neurotic workers in an industrial organisation by means of clinical investigation, there would have to be at least an in-depth interview held with each person. Although it would be possible to categorise some of the 
workers with a reasonable degree of certainty at this initial interview, with many of them a second and even possibly a third corroborative interview would be necessary before they could be diagnosed with any marked degree of certainty. In view of the usually large number of persons involved and the limited number of persons normally available to do the work, this would of necessity be a very time-consuming process and due to possible turn-over of staff amongst these workers, identification could be severely hampered;

\section{Financial implications}

The financial implications involved in the clinical evaluation of neurosis, particularly where this is necessary for research purposes and thus necessarily involves a large number of individuals, is an important factor that must always be borne in mind. Financial considerations are of primary importance to an organisation and research must always be done in such a manner that it combines the principle of financial frugality with the compliance with scientific principles.

\section{Accuracy of prediction}

Anastasi (1968, pp. 151-152) in discussing clinical versus statistical prediction cites a survey by Meehl in 1954 of 20 investigations comparing the two types of prediction. Predictions were made by clinical psychologists, counsellors, psychiatrists and other professional persons with varying amounts of experience in the use of clinical procedures. Meehl showed that, with only one questionable exception, the routine application of statistical procedures yielded at least as many correct predictions as clinical analysis, and frequently more. In this connection, Meehl also called attention to the much greater cost of clinical predictions, in terms of both time and level of personnel required. Anastasi states further that the clinician's chief contributions to diagnosis and prediction are in areas in which satisfactory tests are unavailable.

\section{Psychometric identification}

Psychometric identification of a neurotic personality structure, i.e. the identification by means of scientifically devised apparatus and pencil-and-paper tests, which are quantitatively scored, offers certain definite advantages for research purposes in industry. These advantages, stated briefly, are as follows: 


\section{Group administration}

The tests are usually suitable for group administration. They can be administered to groups of staff as they become available for testing, and the necessity for individual interviews is therefore eliminated.

\section{Specific measurements}

Tests are available to measure specific attributes which are of interest to the researcher. By the careful comparison of tests, those can be selected which will meet his requirements and at the same time confine testing time, and therefore time lost off the job, to a minimum.

\section{Objectivity}

The tests are completely objective and, provided the researcher is consistent in his test instructions and does not introduce extraneous bias, they will measure impartially in respect of all persons subjected to each test.

\section{Standardised scores}

Psychometric tests provide standardised scores which can be used statistically for further manipulation.

\section{Test batteries}

The test can be combined in such a way that they can be used to confirm the results obtained by each. In this way identification of any particular characteristic can be made more certain, i.e. the probability of an incorrect diagnosis can be reduced.

At this point it must be emphasized that all the advantages do not lay with psychometric testing and all the disadvantages with clinical identification. There are two major problems with psychometric testing which can be eliminated during a clinical interview.

These two problems are:

Uncertainty and worry: When workmen in an industrial situation are called in to sit for a series of psychometric tests, they are inclined to worry as to the reason for the tests. Even in a case where the tests are intended purely for research purposes, they find it very difficult to accept that the tests do not hold implications for their immediate and long-term future. Explanations at such test sessions must, of necessity, concentrate on the test/tests to be under- 
gone and the preliminaries to set the test subjects at ease are an ancillary to the test instructions.

In a clinical assessment the problem of uncertainty and worry will be the first point to receive the attention of the psychologist. The assessment will only be made after the individual has been reassured and set at ease.

The possibility of faking: During pencil-and-paper tests the possibility (or even the probability) exists that the testee will not answer all questions perfectly honestly. Most people want to present themselves in the best possible light at all times whenever possible, and if they are able to discern a pattern in the questions or are aware of what the tester is trying to establish, they will answer the questions in the way which, in their opinion, will create the best impression or will please the tester the most.

In a clinical assessment, the psychologist is able to use his professional knowledge to watch for and either eliminate or compensate for this tendency.

\section{THE CHOICE OF MEASUREMENT INSTRUMENTS}

In an industrial situation the industrial psychologist has to work with people en masse and very seldom, comparatively speaking, with individuals in a clinical situation. Where an investigation hinges on the identification of neurosis amongst the staff of a large organisation, these factors will determine the choice of measurement instruments. Instruments have to be chosen which can identify the neurotic personality structure or its elements and at the same time comply with the usual criteria of reliability and validity. In addition the following considerations have to be taken into consideration:

- $\quad$ the instrument should be suitable for use with a large group of staff;

- $\quad$ ease of administration - this entails that the instrument should not only be easy to explain and to use but should be suitable for use with both individuals and groups of staff, depending on how they become available for test administration;

- $\quad$ the instrument should be easy to interpret; and

- $\quad$ the data obtained must be quantifiable so that it can subsequently be statistically manipulated. 
Not all psychometric instruments however, are equally suitable for application in industry as the results of an investigation into the effect of neuroticism on job behaviour indicate (Brophy, 1977). In this particular investigation various tests were considered for the identification of neurotic behaviour in an industrial situation. A number of criteria had to be met and the Eysenck Personality Inventory (E.P.I.), a yes-no inventory which gives direct scores in respect of extraversion and neuroticism, and the Structured-Objective Rorschach Test (SORT) were finally decided upon. The SORT is a multiple choice instrument which uses the 10 original inkblots. It requires neither free association nor inquiry, is suitable for individual or group administration, and can be objectively scored by means of templates. It gives 15 scores from which, by combining the scores in different combinations, 26 traits can be derived. Harris (Buros, 1965, p. 524) states that the SORT provides an assessment of temperament patterns for personnel selection and seems to possess properties which are usually regarded as highly desirable for a research test designed for large scale investigation.

The "behaviour" of the two psychometric instruments as used in this investigation led to interesting insights.

In practice the SORT yielded discouraging results. Even using only the three scores Dd (Pendantic), S (Rigidity) and H (Human Relationships), all three of which the literature studied had indicated were closely correlated with anxiety, there was no correspondence between any single one of them and the results obtained by the E.P.I. In addition the SORT proved to be a very time-consuming instrument to administer, score and then to convert to the SORT Report on the reverse side of the SORT Answer sheet. It is estimated that well in excess of 80 percent of the actual testing time was devoted to the SORT with very little more than 10 percent being required by the scoring of the E.P.I. In view also of its poor reviews in the literature surveyed, its general unreliability and the time it consumes to deliver doubtful results, it is not considered to be a practical method of psychometric testing for use in an industrial situation.

The E.P.I. in practice proved to be a more usable instrument for the psychometric identification of a neurotic personality structure. It was extremely easy to explain because it is basically an uncomplicated instrument. In its administration it gave not the slightest problem and the subjects (who had an average Otis Score of 82) had no trouble in understanding what was required of them. The compiler's claim that the Inventory is suitable for use with persons 
with a lower intellectual level has thus been confirmed. In addition its marking and interpretation is simplified by the fact that it uses a single template and gives a direct score in respect of the two dimensions it measured, namely Extraversion and Neuroticism. It is also very well supported in the literature both in respect of its reliability and its validity for the purpose for which it was constructed.

\section{SUMMARY}

After pointing out some of the practical problems associated with the identification of the neurotic worker in a workforce, two methods of identification which comply with the requirements of being both scientific and accurate, i.e. (1) clinical identification and (2) psychometric identification are discussed. The strengths and shortcomings of clinical identification, when the findings are required for industrial research purposes are contrasted with certain advantages and disadvantages of psychometric identification.

\section{REFERENCES}

Anastasi, A. Psychological Testing. New York: McMillan, 1968.

Brophy, R.H. and Raubenheimer, I.v.W. The effectiveness of Neurotics as Workers. Perspectives in Industrial Psychology, 1978, 4(3).

Brophy, R.H. The Effect of Neuroticism on Job Behaviour. M.Comm thesis. University of Stellenbosch, 1977.

Buros, O. K. The Sixth Mental Measurements Year Book. New Jersey: Gryphon Press, 1965. Coville, W.J., Costello, T.W. and Rouke, I.L. Abnormal Psychology. New York: Barnes Noble, 1960.

Tredgold, R.F. Human Relations in Modern Industry. London: Gerald Duckworth, 1963. 